\title{
Aggressive behaviour among drug-using women from Cape Town, South Africa: ethnicity, heavy alcohol use, methamphetamine and intimate partner violence
}

\author{
Tara Carney ${ }^{1,2^{*}}$ (D), Bronwyn Myers ${ }^{1,2}$, Tracy L. Kline ${ }^{3}$, Kim Johnson ${ }^{1}$ and Wendee M. Wechsberg $3,4,5,6,7$
}

\begin{abstract}
Background: Women have generally been found to be the victims of violence, but scant attention has been paid to the characteristics of women who perpetrate aggression and violence. In South Africa, violence is a prevalent societal issue, especially in the Western Cape.

Method: This study aimed at identifying factors that were associated with aggression among a sample of 720 substance-using women. We conducted multivariate logistic regression to identify factors that are significantly associated with these behaviours.

Results: Ethnicity (Wald $X^{2}=17.07(2), p<0.01$ ) and heavy drinking (Wald $X^{2}=6.60(2), p=0.01$ ) were significantly related to verbal aggression, methamphetamine use was significantly related to physical (Wald $X^{2}=2.73(2), p=0.01$ ) and weapon aggression (Wald $X^{2}=7.94(2), p<0.01$ ) and intimate partner violence was significantly related to verbal (Wald $X^{2}=12.43(2), p<0.01$ ) and physical aggression (Wald $X^{2}=25.92(2), p<0.01$ ).
\end{abstract}

Conclusions: The findings show high levels of aggression among this sample, and highlight the need for interventions that address methamphetamine, heavy drinking and intimate partner violence among vulnerable substance-using women.

Keywords: Substance use, Aggression, Violence, Women, South Africa

\section{Background}

South Africa is a country that is faced with the dual challenges of substance use and violence, with violence being a major contributing factor to death and years lost due to disability [1]. In this country, the Western Cape Province has particularly high levels of substance use disorders and violence perpetration [2, 3]. For example, homicide is a major cause of death in-South Africa, was recorded at 31 per 100, 000 in 2013 in comparison to 6.2 per 100,000 worldwide in a large global study. In

\footnotetext{
* Correspondence: tara.carney@mrc.ac.za

${ }^{1}$ Alcohol, Tobacco and Other Drug Research Unit, South African Medical Research Council, PO Box 19070, Tygerberg 7505, South Africa

${ }^{2}$ Department of Psychiatry and Mental Health, University of Cape Town, Cape Town, South Africa

Full list of author information is available at the end of the article
}

Cape Town, the most recent figures from 2013 are even higher at 59.9\% per 100, 000 deaths [4].

Previous research suggests that substance use is a risk factor for violence and crime perpetration. A number of South African studies have found that intentional injuries from interpersonal violence are often linked to alcohol use [4-6], and a study found associations [7] between substance use and the perpetration of violent crimes. Studies have also documented associations between substance use and the perpetration of intimate partner violence $[8,9]$.

Earlier studies generally focused on men being the perpetrators of violent acts and studied women as the victims. There is a high prevalence of violence against women in some communities in the Western Cape. including among substance-using women whom studies 
have shown are especially vulnerable to interpersonal violence $[10,11]$. While traditionally men who engage in this type of violence have often witnessed it in their childhood and therefore hold traditional views on gender-norms, such gender-disparities in violence perpetration are likely to shift as traditional gender roles in South Africa evolve $[12,13]$. This seems to be the case in high-income countries where increasing rates of violence perpetration by women has been documented. For example, studies have shown that women are becoming increasing verbally aggressive [14] and violent [15] in relationships, in response to interpersonal violence from their male partner [16]. In studies conducted in these high-income countries, substance-using women especially have been found to engage in both physical and verbal aggression [17, 18], regardless of reporting any kind of interpersonal violence. Furthermore, there is emerging evidence that being involved in gang activity is associated with higher levels of substance use and aggressive behavior. For example, a recent study found that young women who self-identify as gang members are more likely to use alcohol and other drugs such as marijuana and report engaging in physically violent behaviours, such as fighting with weapons [19].

While substance-using women from the Western Cape may perpetrate aggressive and violent acts, research on this is lacking. In this region, there has been little research on women as perpetrators of violence. An exception has been a limited number of exploratory studies which found that young substance-using women engaged in physical fights with each other $[20,21]$. However, this earlier work was largely qualitative and did not examine potential age differences in aggressive behaviour among women; despite evidence that suggests that emerging adulthood (1825 years of age) is a high risk period for engaging in high risk behaviours such as substance use and aggressive behaviour [22]. There is also a dearth of existing local research on which demographics factors may predispose substance-using women to being aggressive. This paper aims to address this gap through describing aggressive behaviour among substance-using women in Cape Town, South Africa and exploring potential factors associated with verbal, physical and weapon-using aggression among substance-using women.

\section{Method}

\section{Sample characteristics}

The sample consisted of 720 women from disadvantaged communities in Cape Town who were recruited into a randomised controlled trial of a HIV risk reduction intervention for substance-using women between September 2008 and September 2010. Further details of this study have been reported elsewhere [23]. For this paper, we report only on the baseline characteristics of the sample.
To be included in the study, participants had to be women between 18 and 33 years old, live in one of 15 impoverished peri-urban communities, use at least two types of drugs (including alcohol) at least once a week for the past 3 months, be sexually active with a male partner in the past month, provide informed consent to participate in the study and not have participated in the pilot study.

\section{Research and sampling procedure}

We developed a proportional sampling plan to ensure that recruitment was balanced across the broad range of disadvantaged communities in and around Cape Town. Population estimates were used to calculate representative proportions and determine sample sizes within each community. Trained outreach workers used standard street outreach techniques. Outreach workers visited each community and marketed the study with flyers. Marketing posters were placed in local hangout spots, and outreach workers also spoke to women who were possibly eligible. They also handed out marketing pamphlets to women who were possibly eligible in local hangout spots such as bars, shebeens (local taverns), petrol stations and parks. After obtaining verbal permission to administer a brief screening instrument to assess eligibility, they provided eligible and interested women with an appointment for an intake interview and arrangements were made to transport them to our project site for the interview. At this appointment, women were rescreened and asked to provide informed consent to complete a baseline computer-assisted personal interview (which took approximately $90 \mathrm{~min}$ ) and biological testing for drug use, pregnancy and HIV. Participants were provided with refreshments and a grocery voucher valued at ZAR 40 (USD 3) for their time. Ethics approval for the study was granted by the Institutional Review Boards of RTI International and Stellenbosch University's Health Research Committee (Trial Registration Number: NCT00729391).

\section{Measures}

The Revised Risk Behaviour Assessment (RRBA) [24] was modified for use in South Africa and used to collect self-report information on socio-demographic characteristics such as their current age, ethnicity, income (individual monthly income from any source), employment and years of education. The RRBA also measures drug and alcohol use history, interpersonal violence and HIV risk behaviours. For the current study, the outcome variable of interest was aggressive behaviours. Participants were asked if they had a main sexual partner, namely a boyfriend or husband, who they could either live with or separately from. They were also asked if they experienced any violence by this partner in the past 6 months. 
In terms of alcohol use, participants were asked about the number of drinks they consumed on a typical day when drinking, with heavy drinking being defines as seven or more drinks during this occasion. Average days used in the past month were the measures for methamphetamine and cannabis use.

A modified version of the revised conflict tactics scale (CTS2) was used to measure aggressive behaviour. The CTS2 has been found to have acceptable psychometric properties, with a reliability of 0.89 for items included in the scale [25]. It has also been used in previous studies with women [26]. It consists of 10 items that measure three types of aggression: 1) verbal (insulting, swearing at, threatening); 2) physical (including kicking, hitting, biting and throwing objects) and 3) weapon (gun or knife, threatening with gun or knife) aggression in the previous 3 months. All responses to these items are dichotomous (yes/no). Any affirmative responses were scored as indicative of engagement in that type of aggression.

\section{Data analyses}

To explore relationships between verbal, weapon and physical aggression among women that participated in the study, we first conducted bivariate analysis (chisquare tests of assocation for categorical variables and $t$ tests for continuous variables). We retained demographic variables attaining a significance value of 0.05 or less as potential factors to be controlled in multiple logistic regression models. Three multivariate logistic regression analyses were performed to examine the impact of age, frequency of drinking, cannabis use and methamphetamine use in the past 30 days, and frequency of intimate partner violence in the past 6 months on verbal, physical and weapon aggression in the past 90 days, respectively while adjusting for the potentially confounding effects of the included demographic factors. The SPSS statistical software (version 22) was used for all analysis.

\section{Results}

\section{Sample description}

Out of the total sample $(n=720), 460$ participants (63.89\%) reported engaging in verbal aggression, 292 (40.55\%) reported engaging in physical aggression and 57 (7.92\%) reported aggression with a weapon in the past 3 months (see Table 1). Young women (18-25 years old) were more likely to have engaged in verbal aggression $\left(\mathrm{X}^{2}=5.28, \mathrm{df}=2, p=0.02\right)$, physical aggression $\left(\mathrm{X}^{2}=3.70, \mathrm{df}=2, p=0.05\right)$ and weapon aggression $\left(\mathrm{X}^{2}=8.76, \mathrm{df}=2, p=0.03\right)$ than older women. The majority of women who reported engaging in verbal $\left(\mathrm{X}^{2}=87.57, \mathrm{df}=2, p<0.01\right)$ and physical $\left(\mathrm{X}^{2}=56.51\right.$, $\mathrm{df}=2, \mathrm{p}<0.01)$ aggression self-identified as "Coloured" (of mixed race ancestry).

Women with a lower mean monthly income were significantly more likely to have reported engaging in verbal $(t=2.93, \mathrm{df}=718, \mathrm{p}<0.01)$ and physical aggression $(t=4.61, \mathrm{df}=718, p<0.01)$. Compared to employed women, unemployed women were more likely to report engaging in verbal aggression $\left(\mathrm{X}^{2}=4.28, \mathrm{df}=2, p=0.04\right)$ but not physical or weapon aggression.

\section{Substance use and intimate partner violence}

For substance use, women who had a higher average methamphetamine use over the past 30 days were significantly more likely to report all three types of aggression (verbal: $t=1.98, \mathrm{df}=495, p=0.05$; physical: $t=3.09$,

Table 1 Factors associated with types of aggression among substance-using women $(n=720)$

\begin{tabular}{|c|c|c|c|c|c|c|c|c|c|}
\hline Measure & $\begin{array}{l}\text { Verbal } \\
\text { Aggression } \\
(n=460)\end{array}$ & $\begin{array}{l}\text { Test Statistic } \\
{\left[t(d f) \text { or } x^{2}(d f)\right]}\end{array}$ & $p$ & $\begin{array}{l}\text { Physical } \\
\text { Aggression } \\
(n=292)\end{array}$ & $\begin{array}{l}\text { Test Statistic } \\
{\left[t(d f) \text { or } x^{2}(d f)\right]}\end{array}$ & $p$ & $\begin{array}{l}\text { Weapon } \\
\text { Aggression } \\
(n=57)\end{array}$ & $\begin{array}{l}\text { Test Statistic } \\
{\left[\mathrm{t}(d f) \text { or } x^{2}(d f)\right]}\end{array}$ & $p$ \\
\hline \multicolumn{10}{|l|}{ Demographics } \\
\hline Age (Emerging adult*) & $315(68.5 \%)$ & $5.28(2)$ & $0.02^{*}$ & $197(67.5 \%)$ & $3.70(2)$ & $0.05^{*}$ & $31(54.4 \%)$ & $8.76(2)$ & $0.03^{*}$ \\
\hline Ethnicity ("Coloured") & $313(68.0 \%)$ & $87.57(2)$ & $<0.01^{*}$ & $210(71.9 \%)$ & $56.51(2)$ & $<0.01^{*}$ & $40(70.2 \%)$ & $5.79(2)$ & 0.02 \\
\hline $\begin{array}{l}\text { Average income in past } \\
\text { month }(M, S D)\end{array}$ & $306.39(458.50)$ & $2.93(718)$ & $<0.01^{*}$ & $366.61(501.43)$ & $4.61(718)$ & $<0.01^{*}$ & 312.63 (396.46) & $0.75(718)$ & 0.45 \\
\hline $\begin{array}{l}\text { High school education } \\
\text { Incomplete (Yes) }\end{array}$ & $414(90.0 \%)$ & $1.52(2)$ & 0.27 & $266(91.1 \%)$ & $2.42(2)$ & 0.12 & $52(91.2 \%)$ & $0.34(2)$ & 0.56 \\
\hline Unemployed (Yes) & $422(91.7 \%)$ & $4.28(2)$ & $0.04^{*}$ & $268(91.8 \%)$ & $1.71(2)$ & 0.19 & $52(91.2 \%)$ & $0.10(2)$ & 0.75 \\
\hline \multicolumn{10}{|l|}{ Substance Use } \\
\hline Cannabis Use (M, SD) & $14.47(12.05)$ & $1.61(562)$ & 0.12 & $14.15(11.98)$ & $1.57(668)$ & 0.16 & $15.83(12.38)$ & $0.52(668)$ & 0.60 \\
\hline $\begin{array}{l}\text { Methamphetamine } \\
\text { Use }(M, S D)\end{array}$ & $14.35(9.67)$ & $1.98(495)$ & $0.05^{*}$ & $15.18(9.96)$ & 3.09 (495) & $<0.01^{*}$ & $18.49(10.25)$ & $3.50(495)$ & $<0.01^{*}$ \\
\hline Heavy Drinking & $208(45.1 \%)$ & $35.1(2)$ & $<0.01^{*}$ & $147(55.1 \%)$ & $35.3(2)$ & $<0.01^{*}$ & $28(49.1 \%)$ & $3.2(2)$ & 0.08 \\
\hline $\begin{array}{l}\text { Main Sexual Partner } \\
\text { Violence }(M, S D)\end{array}$ & $8.84(10.21)$ & $9.21(685)$ & $<0.01^{*}$ & $11.13(10.43)$ & $10.16(441)$ & $<0.01^{*}$ & $11.89(11.75)$ & $3.28(52)$ & $<0.01^{*}$ \\
\hline
\end{tabular}


$\mathrm{df}=495, p<0.01$; weapon: $t=3.50, \mathrm{df}=2, \mathrm{p}<0.01)$. Heavy drinking was also associated with verbal $\left(X^{2}=35.10, p<0.01\right)$ and physical aggression $\left(X^{2}=35.30\right.$, $\mathrm{p}<0.01)$. Women who reported engaging in all three kinds of aggression reported a significantly higher average number of days of partner sexual violence in the previous 6 months $(t=9.21, \mathrm{df}=685, p<0.01 ; t=10.16, \mathrm{df}=441$, $\mathrm{p}<0.01 ; t=3.28, \mathrm{df}=52, \mathrm{p}<0.01)$. Education was not entered into any of the three regression models, and nor was employment for physical and weapon regression $(p>0.05$ in bivariate analysis).

\section{Multivariate analysis}

Ethnicity was significantly associated with verbal aggression (Wald $\mathrm{X}^{2}=17.07(2), \mathrm{p}<0.01$ ) but not physical or weapon aggression after adjusting for other possible confounding influences in the multiple logistic regression models (Table 2). "Coloured" women were more than three times as likely to report engaging in verbal aggression as black African women (AOR: 3.94; 95\% CI: 2.416.47). Heavy drinking was also significantly associated with verbal aggression (Wald $X^{2}=6.60(2), p=0.01$ ), where women who reported heavy drinking were almost twice as likely to be verbally aggressive than women who did not report this pattern of drinking (AOR: 1.96; CI: 1.17-3.28). Methamphetamine use was significant associated with physical (Wald $\mathrm{X}^{2}=2.73(2), \mathrm{p}=0.01$ ) and weapon aggression (Wald $\mathrm{X}^{2}=7.94$ (2), $p<0.01$ ). Women who used methamphetamine had greater odds of engaging in both forms of aggressive behaviour relative to women who used other substances (physical: AOR: 1.03; 95\% CI: 2.41-6.47; weapon: AOR: 1.05; 95\% CI: 1.02-1.09). Finally, intimate sexual partner violence in the previous 6 months was significantly associated with engaging in verbal (Wald $\mathrm{X}^{2}=12.43(2), \mathrm{p}<0.01$ ) and physical aggression (Wald $\left.\mathrm{X}^{2}=25.92(2), \mathrm{p}<0.01\right)$. After controlling for the influence of other confounding variables, women who reported intimate sexual partner violence had significantly greater odds of being verbally (AOR: 1.06; CI: 1.03-1.10) and physically (AOR: 1.07; CI: 1.04-1.10) aggressive than women without this exposure.

\section{Discussion}

This study is one of the first to report on substanceusing women's engagement in various forms of aggressive behaviour, as opposed to being the target of aggression and violence. To the best of our knowledge, there have been limited studies on women's perpetration of aggression or factors that may influence aggressive behaviour among women. Our findings show that an high proportion of substance-using women engaged in recent acts of aggression. This is a concerning trend as it may increase the risk that violence will be perpetrated against them as indicated by previous studies $[8,14]$ and may perpetuate cycles of substance use and violence towards women that are often experienced in these communities [27].

The study also sheds some light on which factors that potentially increase substance-using women's risk of being aggressive. Age was not significantly associated with aggressive behaviour. A possible reason was that the age range of the sample was restricted, with all participants being 33 years old and younger This could possibly explain why the current findings were different to [28] who found that those in emerging adulthood are more

Table 2 Logistic regression analysis of variables on aggression-related outcomes

\begin{tabular}{|c|c|c|c|c|c|}
\hline Outcome & Covariate & Wald Test Statistic & $\mathrm{AOR}^{*}$ & $p$-value & $95 \% \mathrm{Cl}$ \\
\hline Verbal aggression & $\begin{array}{l}\text { Age (Emerging adult) } \\
\text { Ethnicity (Coloured) } \\
\text { Income } \\
\text { Employment } \\
\text { Cannabis use } \\
\text { Methamphetamine Use } \\
\text { Heavy Drinking } \\
\text { Main Sexual Partner Violence }\end{array}$ & $\begin{array}{l}0.50 \\
17.07 \\
0.04 \\
2.76 \\
1.27 \\
1.74 \\
6.60 \\
12.43\end{array}$ & $\begin{array}{l}0.81 \\
3.23 \\
1.00 \\
2.36 \\
1.01 \\
1.02 \\
1.96 \\
1.06\end{array}$ & $\begin{array}{l}0.48 \\
<0.01^{*} \\
0.85 \\
0.10 \\
0.26 \\
0.19 \\
0.01^{*} \\
<0.01^{*}\end{array}$ & $\begin{array}{l}0.44-1.47 \\
1.85-5.63 \\
1.00-1.00 \\
0.86-6.47 \\
0.99-1.03 \\
0.99-1.04 \\
1.17-3.28 \\
1.03-1.10\end{array}$ \\
\hline Physical aggression & $\begin{array}{l}\text { Age (Emerging adult) } \\
\text { Ethnicity (Coloured) } \\
\text { Income } \\
\text { Cannabis use } \\
\text { Methamphetamine Use } \\
\text { Heavy Drinking } \\
\text { Main Sexual Partner Violence }\end{array}$ & $\begin{array}{l}0.22 \\
1.70 \\
1.90 \\
0.55 \\
2.73 \\
2.73 \\
25.92\end{array}$ & $\begin{array}{l}0.89 \\
1.42 \\
1.00 \\
1.01 \\
1.03 \\
1.46 \\
1.07\end{array}$ & $\begin{array}{l}0.64 \\
0.19 \\
0.17 \\
0.46 \\
0.01^{*} \\
0.10 \\
<0.01^{*}\end{array}$ & $\begin{array}{l}0.53-1.48 \\
0.84-2.42 \\
1.00-1.00 \\
0.99-1.03 \\
1.01-1.05 \\
0.93-2.29 \\
1.04-1.10\end{array}$ \\
\hline Weapon aggression & $\begin{array}{l}\text { Age (Emerging adult) } \\
\text { Ethnicity (Coloured) } \\
\text { Income } \\
\text { Cannabis use } \\
\text { Methamphetamine Use } \\
\text { Heavy Drinking } \\
\text { Main Sexual Partner Violence }\end{array}$ & $\begin{array}{l}0.94 \\
0.59 \\
0.02 \\
2.61 \\
7.94 \\
0.10 \\
3.77\end{array}$ & $\begin{array}{l}0.67 \\
1.47 \\
1.00 \\
1.03 \\
1.05 \\
1.04 \\
1.04\end{array}$ & $\begin{array}{l}0.33 \\
0.44 \\
0.96 \\
0.11 \\
<0.01^{*} \\
0.75 \\
0.05\end{array}$ & $\begin{array}{l}0.31-1.49 \\
0.55-3.93 \\
1.00-1.00 \\
1.00-1.10 \\
1.02-1.09 \\
0.54-2.35 \\
1.00-1.07\end{array}$ \\
\hline
\end{tabular}


likely to be aggressive and violent than older women in established adulthood. Since violence and aggression is so entrenched in the Western Cape region [3,29], it is possible that women have been exposed to violence for a large proportion of their life, and therefore many women may become aggressive themselves at any age. Previous studies have also shown that there is indeed a long history of violence in South Africa [30].This is especially the case in the Western Cape, where substance-using women have been exposed to an entrenched gang-culture related to violence [21], and there is also evidence that violence against women is inter-generationally transmitted, especially domestic violence [8].

In terms of ethnicity, we found that "Coloured" women had significantly greater odds of self-reporting being verbally aggressive than Black African women. This matches what was found in a previous study with young women, where "Coloured" women reported violence due to substance use and gang violence, with gang initiation involving acts of violence for young women [21]. However, future research is needed as to explain why verbal aggression specifically may be linked to ethnicity.

The study findings also indicated that heavy drinking was significantly associated with verbal aggression after adjusting for confounding variables. This is in keeping with findings from studies with heterosexual couples that found that women are more likely to engage in verbal aggression following alcohol use [17, 30]. The heavy use of alcohol was not related to any physically violent behaviour, as it has been in previous studies with women in specific alcohol-serving settings [18].

Methamphetamine use was significantly related to both physical and weapon aggression. The use of this drug seems to increase the likelihood of women engaging in acts of violence. This finding echoes previous studies conducted in the Western Cape that included women [31, 32], where methamphetamine has been found to be related to the perpetration of aggressive behaviour. Recent research has shown that users' ability to control or inhibit their aggressive impulses are affected by methamphetamine [33], which could account for heightened aggression and violent behaviour among people who use methamphetamine.

These findings suggest that in order to reduce the perpetration of violence among substance-using women, interventions that focus on the reduction of methamphetamine and heavy alcohol consumption are needed. While methamphetamine use has been found to be prevalent in previous studies with substance-using women in disadvantaged communities [34, 35], treatment for methamphetamine use is still not always accessible for women from these communities, despite high levels of treatment readiness [36, 37]. Providing services that reach such vulnerable substanceusing women is therefore key. These services should not only address the substance use, but should also teach women conflict resolution strategies that equip them to manage conflictual situations and limit frustration that may lead to verbal or physical aggression. This is not only important for reducing acts of aggression but also for preventing women from becoming victims of violence.

Another major finding was that participants who had experienced recent violence by their main sexual partner were significantly more likely to exhibit verbal and physical aggression. This is not altogether surprising, since research has found that substance-using women in the Western Cape are at increased risk of interpersonal violence [10]. It is possible that being the victim of intimate partner violence may result in women becoming aggressive and violent themselves [16] if this trauma is left untreated. This may continue the cycle of violence in relationships and can extend to other individuals that encounter substance-using women. To break this cycle, women need access not only to substance use services, but also to trauma and gender-based violence services. In South Africa, there are many barriers to substance-using women accessing mental health services that include trauma support [27]. A previous study conducted in Cape Town found evidence that women do not have equal opportunities to substance use treatment, with barriers including affordability and accessibility to treatment, and concerns about stigma (39). Trauma-informed substance use services are needed for women to prevent the progression of substance use as well as violent behaviour.

These findings need to be considered in the light of several limitations. First, the measurement of aggression was a secondary outcome in the current study, with the focus being on substance use, interpersonal violence and sexual risk. Therefore, the questions around aggression and violence perpetration did not examine the reasons behind aggressive behavior or the relationship that they had with the person towards whom they were aggressive. More research is needed to better understand the perpetration of aggressive behaviour by substance-using women. Second, the sample was recruited from disadvantaged urban communities in greater Cape Town, and it is not known if these findings are representative of other substance-using women in the province or the country. Third, the study did not include young women under the age of 18 years old, and previous work has indicated that adolescence is a developmental period where high risk behaviours are common, including aggression. This highlights the need to further explore these high risk behaviours among younger substanceusing women.

\section{Conclusion}

This article provides evidence for high levels of recent aggressive and violent behaviour among substance-using 
women from poor communities in Cape Town, South Africa. This perpetration of aggressive behaviour should be addressed as this may place women at an elevated risk for exposure to interpersonal violence and legal consequences. Current findings suggest that women who use methamphetamine, drink heavily and have experienced recent intimate partner violence are especially likely to report being aggressive. Comprehensive interventions are needed that provide treatment for substance use disorders, teach women to resolve conflicts without aggression, and provide trauma services for women who have been exposed to physical or sexual violence. Barriers to mental health services for women will also need to be addressed. As South Africa is a highly violent society, identifying the antecedents of aggression and violent behaviour and addressing these in a systematic way to reduce levels of violence is of critical importance to the public health of the country.

\section{Abbreviations}

AOR: Adjusted Odds Ratio; Cl: Confidence Intervals; CTS2: Conflict Tactics Scale 2; HIV: Human immunodeficiency virus; RRBA: Revised risk behavior assessment; RTI: Research Triangle Institute

\section{Acknowledgements}

Not applicable

\section{Funding}

This study was funded by the Eunice Kennedy Shriver National Institute of Child Health and Human Development (NICHD) R01 HD058320 (Wechsberg). The content of this manuscript care solely the responsibility of the authors and do not necessarily represent the official views of the $\mathrm{NIH}$. The $\mathrm{NIH}$ had no further role in the study design; in the collection, analysis and interpretation of data; in the writing of the paper; or in the decision to submit the paper for publication.

\section{Availability of data and materials}

The data that support the findings of this study are available from RTI International but restrictions apply to the availability of these data, which were used under license for the current study, and so are not publicly available. Data are however available from the authors upon reasonable request and with permission of RTI International.

\section{Authors' contributions \\ TC was involved in the managing the study and was responsible for planning, writing and reviewing all aspects of the manuscript. TLK conducted the statistical analyses with inputs from TC and assisted with writing the methods. BM, KJ and WMW reviewed the draft manuscript and provided critical comments. WMW is the principal investigator for this project and takes responsibility for the integrity of the data and the accuracy of the data analysis. She is the senior author on this paper and provided inputs into every aspect of the paper. All authors read and approved the final draft.}

\section{Ethics approval and consent to participate}

Ethics approval for the study was granted by the Institutional Review Boards of RTI International and Stellenbosch University's Health Research Committee (Trial Registration Number: NCT00729391). All participants completed informed consent in order to participate in the study.

\section{Consent for publication}

Not applicable

\section{Competing interests}

The authors declare that they have no competing interests.

\section{Publisher's Note}

Springer Nature remains neutral with regard to jurisdictional claims in published maps and institutional affiliations.

\section{Author details}

${ }^{1}$ Alcohol, Tobacco and Other Drug Research Unit, South African Medical Research Council, PO Box 19070, Tygerberg 7505, South Africa. ${ }^{2}$ Department of Psychiatry and Mental Health, University of Cape Town, Cape Town, South Africa. ${ }^{3}$ Substance Use Gender, and Applied Research Program, Research Triangle Park, RTI, 3040 Cornwallis Road, Chapel Hill, NC 27709, USA. ${ }^{4}$ RTI Gender Global Gender Center, Research Triangle Park, 3040 Cornwallis Road, Chapel Hill, NC 27709, USA. ${ }^{5}$ Health, Policy and Administration, Gillings School of Global Public Health, The University of North Carolina, Chapel Hill, NC, USA. ${ }^{6}$ Psychology in the Public Interest, North Carolina State University, Raleigh, NC, USA. ${ }^{7}$ Psychiatry and Behavioral Sciences, School of Medicine, Duke University, Durham, NC, USA.

Received: 1 September 2016 Accepted: 20 September 2017

Published online: 30 September 2017

\section{References}

1. Seedat M, Van Niekerk A, Jewkes R, Suffla S, Ratele K. Violence and injuries in South Africa: prioritising an agenda for prevention. Lancet. 2009;374:68-79.

2. Herman AA, Stein DJ, Seedat S, Heeringa SG, Moomal H, Williams DR. The South African Stress and Health (SASH) study: 12-month and lifetime prevalence of common mental disorders. S Afr Med J. 2009:99(5):339-44.

3. Matzopoulis R, Myers JE. The Western Cape Government's new integrated provincial violence prevention policy framework: successes and challenges. Aggress Violent Behav. 2014;19(6):649-54

4. Parry $\mathrm{CDH}$, Dewing S. A public health approach to addressing alcoholrelated crime in South Africa. Afr J Drug Alcohol Stud. 2006;5:41-56.

5. Nicol A, Knowlton LM, Schuurman N, Matzopoulos R, Zargaran E, Cinnamon J, et al. Trauma surveillance in Cape Town, South Africa: an analysis of 9236 consecutive trauma center admissions. JAMA Surg. 2014;149(6):549-56.

6. Schuurman N, Cinnamon J, Walker B, Fawcett V, Nicol A, Hameed SM, et al. Intentional injury and violence in Cape Town, South Africa: an epidemiological analysis of trauma admissions data. Glob Health Action. 2015:8:20716.

7. Parry $\mathrm{CDH}$, Plüddemann $\mathrm{A}$, Louw $\mathrm{A}$, Leggett $\mathrm{T}$. The 3-metros study of drugs and crime in South Africa: findings and policy implications. Am J Drug Alcohol Abuse. 2004;30:167-85.

8. Abrahams N, Jewkes R, Hoffman M, Laubsher R. Sexual violence against intimate partners in Cape Town: prevalence and risk factors reported by men. Bull World Health Organ. 2004:82(5):330-7.

9. S-KK M, Wechsberg WM, Luseno WK. Exploring the differences and similarities between Black/African and Coloured men regarding violence against women, substance abuse, and HIV risks in Cape Town, South Africa. Psychol Men Masculinity. 2009:10(1):13-29.

10. Reed E, Myers B, Novak SP, Browne FA, Wechsberg WM. Experiences of violence and association with decreased drug abstinence among women in Cape Town, South Africa. AIDS Behav. 2015;19(1):192-8.

11. Wechsberg WM, Myers B, Reed E, Carney T, Emanuel AN, Browne FA. Substance use, gender inequity, violence and sexual risk among couples in Cape Town. Cult Health Sex. 2013;15(10):1221-36.

12. Kalichman SC, Simbayi LC, Kaufman M, Cain D, Cherry C, Jooste S, Mathiti V. Gender attitudes, sexual violence, and HIV/AIDS risks among men and women in Cape Town, South Africa. J Sex Res. 2005:42:299-305.

13. Peacock D, Khumalo B, McNab E. Men and gender activism in South Africa: Observations, critique, and recommendations for the future. Agenda. 2006; 69:76-82.

14. Bookwala J, Sobin J, Zdaniuk B. Gender and aggression in marital relationships: A life-span perspective. Sex Roles. 2005;52:797-806. doi: 10.1007/s11199-005-4200-1.

15. Swan SC, Gambone LJ, Caldwell JE, Sullivan TP, Snow DL. A Review of Research on Women's Use of Violence with Male Intimate Partners. Violence Vict. 2008:23(3):301-14

16. Swan SC, Snow DL. The development of a theory of women's use of violence in intimate relationships. Violence Against Women. 2006:12:1026-45.

17. Newberry M, Williams N, Caulfield L. Female alcohol consumption, motivations for aggression and aggressive incidents in licensed premises. Addict Behav. 2013;38(3):1844-51. 
18. Spence CE, Williams SE, Gannon TA. It's your round!' - female aggression in licensed premises. Psychol Crime Law. 2009;15:269-84.

19. Wechsberg WM, Doherty IA, Browne FA, Kline TK, Carry MG, Raiford JL, et al. Gang membership and marijuana use among African American female adolescents in North Carolina. Subst Abuse Rehabil. 2015;6:141-50.

20. Sawyer K, Wechsberg WM, Myers B. Cultural similarities and differences between a sample of Black/African and Coloured women in South Africa: convergence of risk related to substance use, sexual behavior, and violence. Womens Health. 2006:43:73-92.

21. Sawyer-Kurian KM, Browne FA, Carney T, Petersen P, Wechsberg WM. Exploring the intersecting health risks of substance abuse, sexual risk, and violence for female South African teen dropouts. J Psychol Afr. 2011;21:15-25.

22. Nelson $\amalg$, Barry $C M$. Distinguishing features of emerging adulthood. J Adolesc Res. 2005;20:242-62.

23. Wechsberg WM, Jewkes R, Novak SP, Kline T, Myers B, Browne FA, Carney T, Morgan Lopez AA, Parry C. A brief intervention for drug use, sexual risk behaviours and violence prevention with vulnerable women in South Africa: A randomised trial of the Women's Health CoOp. BMJ Open. 2013;3: e002622.

24. Wechsberg WM. Revised Risk Behavior Assessment (RBA), Part I and Part II. North Carolina: Research Triangle Institute; 1998.

25. Straus MA, Hamby SL, Boney-McCoy S. The Revised Conflict Tactics Scales (CTS2): development and preliminary psychometric data. J Fam Issues. 1996; 17:283-316.

26. Wechsberg WM, Lam WK, Zule W, Hall G, Middlesteadt R, Edwards J. Violence, homelessness, and HIV risk among crack-using African-American women. Subst Use Misuse. 2003;38:671-701.

27. Myers B, Carney T, Wechsberg WM. "Not on the agenda": A qualitative study of influences on health services use among poor young women who use drugs in Cape Town, South Africa. Int J Drug Policy. 2016;30:52-8.

28. Nelson DA, Springer MM, Nelson LJ, Bean NH. Normative beliefs regarding aggression in emerging adulthood. Soc Dev. 2008;17(3):638-60.

29. Norman R, Matzopoulos R, Groenewald P, Bradshaw D. The high burden of injuries in South Africa. Bull World Health Organ. 2007;85(9):695-702.

30. Testa M, Derrick JL. A daily process examination of the temporal association between alcohol use and verbal and physical aggression in community couples. Psychol Addict Behav. 2014:28(1):127-38.

31. Plüddemann A, Flisher AJ, Mathews C, Parry CDH, Lombard CA Methamphetamine use, aggressive behaviour and other mental health issues among high-school students in Cape Town, South Africa. Drug Alcohol Depend. 2010;109:14-9.

32. Watt MH, Myers B, Towe SL, Meade CS. The mental health experiences and needs of methamphetamine users in Cape Town: A mixed-methods study. S Afr Med J. 2015:105(8):685-8.

33. Dawe $S$, Davis $P$, Lapworth $K$, McKetin R. Mechanisms underlying aggressive and hostile behavior in amphetamine users. Curr Opin Psychiatry. 2009; 22(3):269-73.

34. Myers B, Kline T, Browne FA, Carney T, Parry C, Johnson K, et al. Ethnic differences in alcohol and drug use and related sexual risks for HIV among vulnerable women in Cape Town, South Africa: implications for interventions. BMC Public Health. 2013;13:174.

35. Wechsberg WM, Luseno W, Riehman K, Kar R, Browne F, Parry C. Substance use and sexual risk within the context of gender inequality in South Africa. Subst Use Misuse. 2008;43(8-9):1186-201.

36. Meade CS, Towe S, Watt MH, Skinner D, Myers B, Kimani S, et al. Addiction and barriers to treatment in a sample of community-recruited methamphetamine users in a South African township. Drug Alcohol Depend. 2015;146:e37.

37. Myers B, Fakier N. Provision of mental health services in South African substance abuse treatment facilities. Int J Ment Health Addict. 2009;7(3): $441-9$

\section{Submit your next manuscript to BioMed Central and we will help you at every step:}

- We accept pre-submission inquiries

- Our selector tool helps you to find the most relevant journal

- We provide round the clock customer support

- Convenient online submission

- Thorough peer review

- Inclusion in PubMed and all major indexing services

- Maximum visibility for your research

Submit your manuscript at www.biomedcentral.com/submit

) Biomed Central 